Erratum

\title{
Erratum to "Site-Specific Antioxidative Therapy for Prevention of Atherosclerosis and Cardiovascular Disease"
}

\author{
Hajime Otani \\ Internal Medicine II, Kansai Medical University, Moriguchi City, Japan \\ Correspondence should be addressed to Hajime Otani; otanih@takii.kmu.ac.jp \\ Received 6 September 2013; Accepted 12 September 2013 \\ Copyright (C) 2013 Hajime Otani. This is an open access article distributed under the Creative Commons Attribution License, which \\ permits unrestricted use, distribution, and reproduction in any medium, provided the original work is properly cited.
}

The Research Grant number in Acknowledgments section in page 9 stating that "This work was supported in part by Research Grant 20590847" was wrong and the corrected one is " $23591070 . "$ 


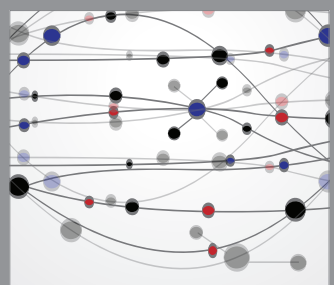

The Scientific World Journal
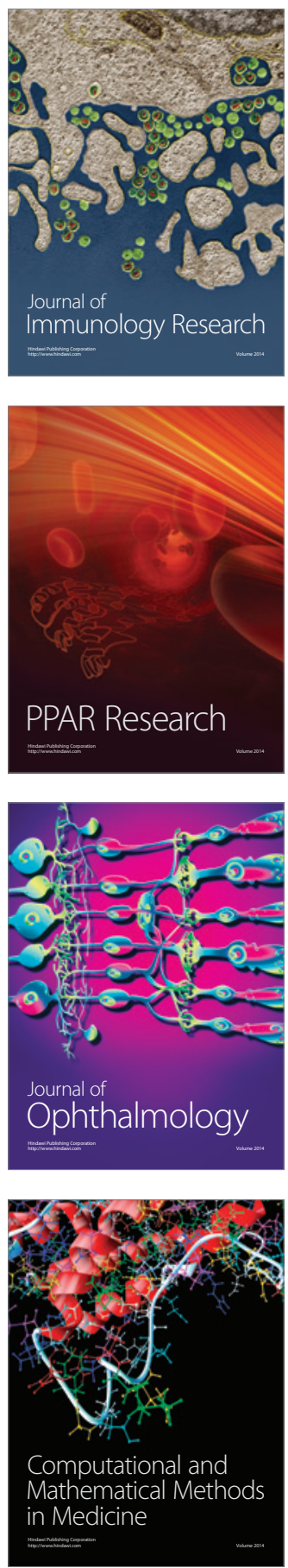

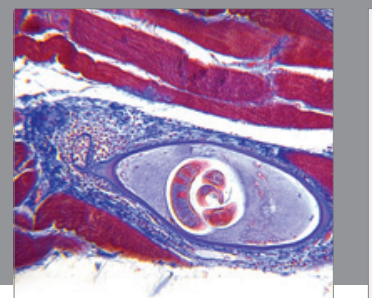

Gastroenterology

Research and Practice
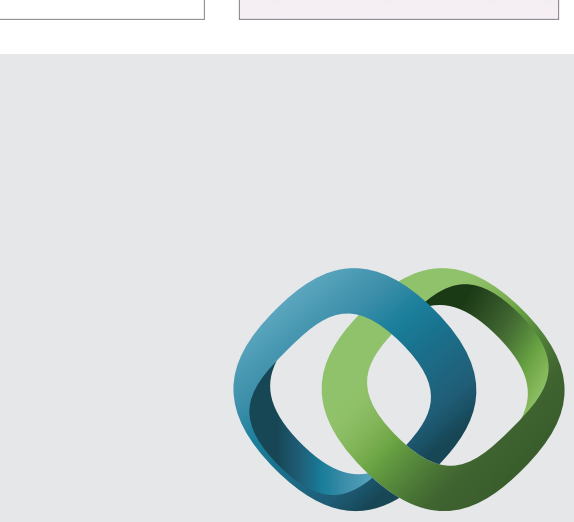

\section{Hindawi}

Submit your manuscripts at

http://www.hindawi.com
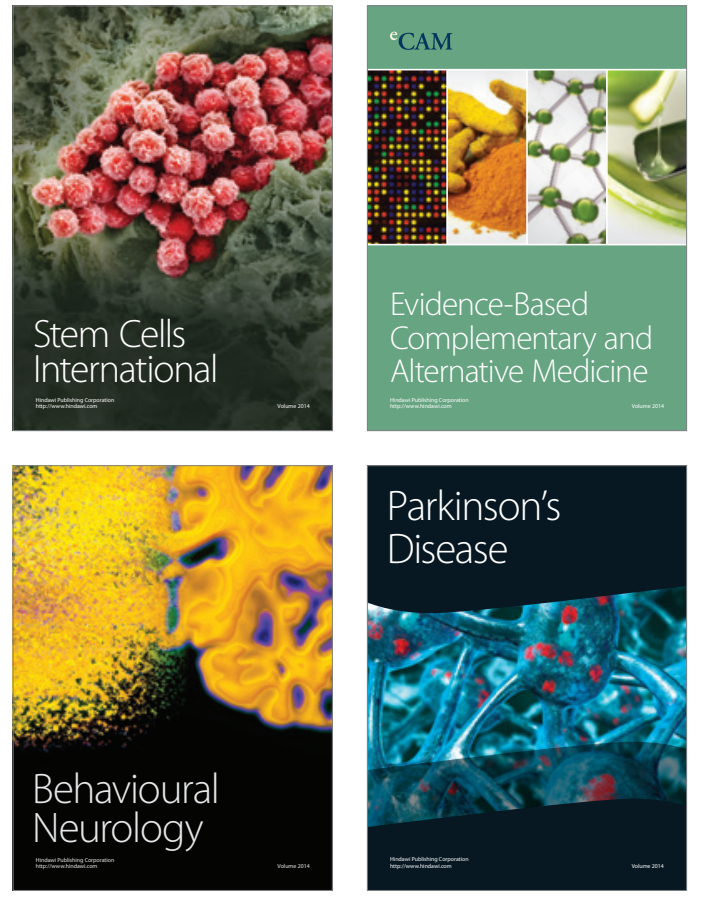
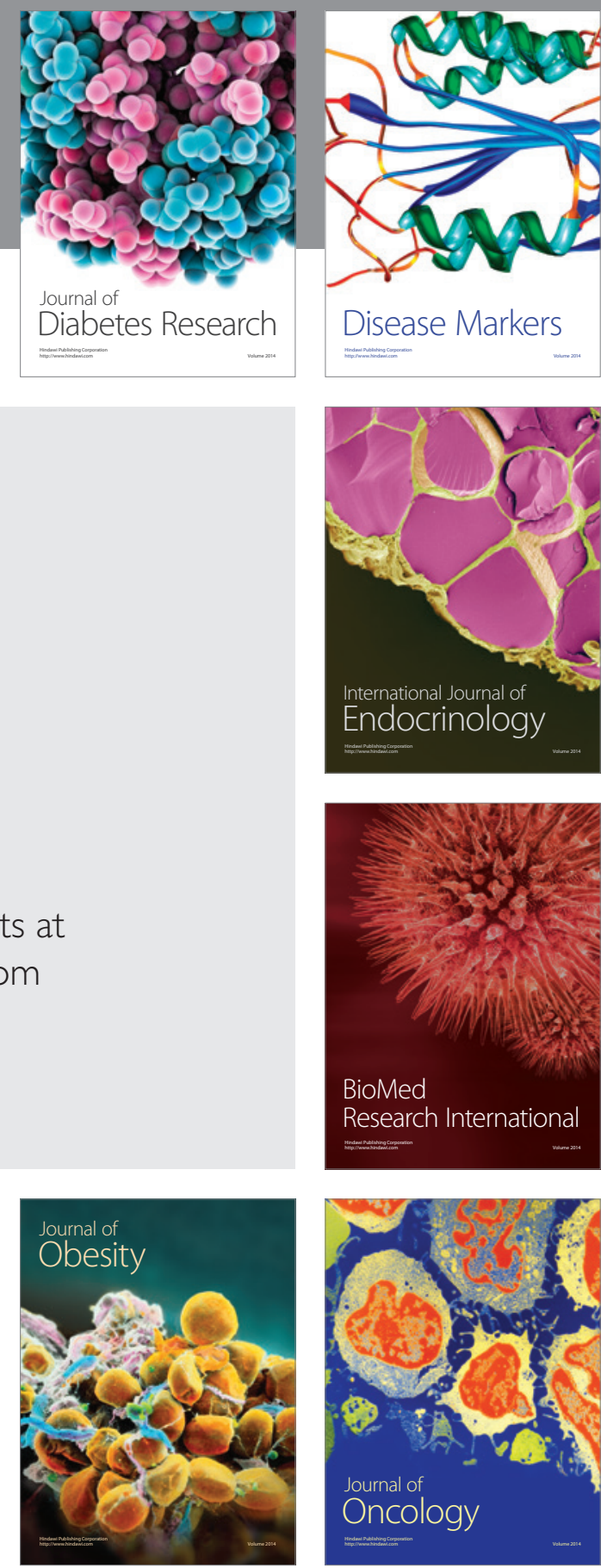

Disease Markers
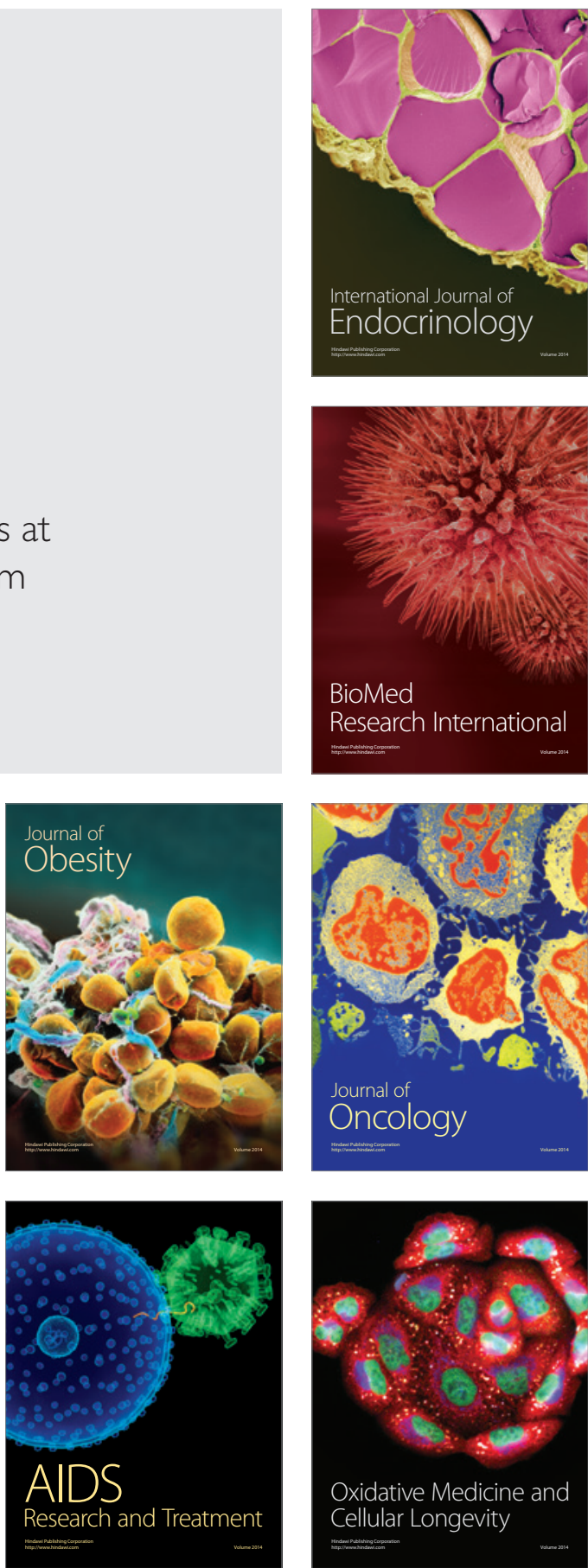